EGU21-13264, updated on 18 May 2021

https://doi.org/10.5194/egusphere-egu21-13264

EGU General Assembly 2021

(c) Author(s) 2021. This work is distributed under

the Creative Commons Attribution 4.0 License.

\title{
The record of the Eocene-Oligocene Transition and the "Grande Coupure". Magnetostratigraphic constraints from the Ebro Basin revisited.
}

\author{
Miguel Garcés ${ }^{1}$, Elisabet Beamud ${ }^{1,2}$, Miguel López-Blanco ${ }^{1}$, Manuel Gómez ${ }^{3}$, Elisenda Costa ${ }^{4}$, \\ Alberto Sáez ${ }^{1}$, and Luis Cabrera ${ }^{1}$ \\ ${ }^{1}$ Geomodels Research Institute, Dept Earth and Ocean Dynamics, University of Barcelona, Barcelona, Spain \\ (mgarces@ub.edu) \\ ${ }^{2}$ Paleomagnetic Laboratory CCiTUB-ICTJA CSIC, Barcelona, Spain \\ ${ }^{3}$ Sant Pere 7, Vilafranca del Penedès, Spain \\ ${ }^{4}$ Institut Torrent de les Bruixes, Santa Coloma de Gramanet, Spain
}

Magnetostratigraphy is the key to put disparate chronological pieces together in a consistent chronostratigraphic framework. Provided that a long continuous record of reversals can be obtained from the sedimentary record, a correlation with the GPTS may be established. Magnetostratigraphy provides added value to the chronology as long as it keeps certain independence from external age constraints, such as bioevents calibrated elsewhere or radiochronologic data.

An independent correlation is meant to not be anchored to a given chron on the basis of an external age constrain. Our experience recommends that external age constraints are best taken with flexibility, allowing for the searching of a best fit between the magnetic polarity sequence (in meters) and the GPTS (in million-years). This rationale relies on the fact that the Geological Time Scale is the tool that allows earth-scientist of many varied disciplines to understand and discuss about the dimension of time. But the time scale calibration is a task in continuous refinement. As the accuracy and precision of the dating tools increases, our ability to unravel lag times in geological processes increases too. As more refined data is produced, the calibration of the time scale reveals as an ongoing task rather than a final product.

Here we present the case of the Eocene-Oligocene Transition (EOT) as recorded in alluviallacustrine sediments of the eastern Ebro Basin. An earlier work provided a magnetostratigraphic correlation that was in agreement with small-mammals biostratigraphic data. A key constraint to this study was the Santpedor locality, which yielded a characteristic post-Grand Coupure small mammal assemblage, then attributed to the lowest Oligocene.

An extended record of the magnetostratigraphy has challenged the earlier correlation and puts forward an alternate scenario that reveals a misfit with earlier and recent biochronological interpretations of the fossil mammal record. The significance of this discrepancy in terms of heterochrony of biostratigraphic events, the punctuated character of faunal replacement across 
the EOT, and time lags between the marine and continental realms may need to be addressed. 